\title{
Slow clearance of Plasmodium vivax with chloroquine amongst children younger than six months of age in the Brazilian Amazon
}

\author{
André M Siqueira ${ }^{1,2} /{ }^{+}$, Lucas I Coutinho', Rafael L Gurgel ${ }^{1}$, Willian CS Su' ${ }^{1}$, Luiz M Carvalho ${ }^{2}$, \\ Silvana G Benzecry ${ }^{1}$, Aline CC Alencar ${ }^{1}$, Márcia AA Alexandre ${ }^{1,2,3}$, \\ Maria Graças C Alecrim ${ }^{1,2}$, Marcus VG Lacerda ${ }^{1,2} /+$ \\ 'Universidade do Estado do Amazonas, Manaus, AM, Brasil \\ ${ }^{2}$ Fundação de Medicina Tropical Dr Heitor Vieira Dourado, Manaus, AM, Brasil ${ }^{3}$ Nilton Lins University, Manaus, AM, Brasil
}

\begin{abstract}
Plasmodium vivax is the most widespread parasite causing malaria, being especially prevalent in the Americas and Southeast Asia. Children are one of the most affected populations, especially in highly endemic areas. However, there are few studies evaluating the therapeutic response of infants with vivax malaria. This study retrospectively evaluated the parasitaemia clearance in children diagnosed with vivax malaria during the first five days of exclusive treatment with chloroquine (CQ). Infants aged less than six months old had a significantly slower parasitaemia clearance time compared to the group of infants and children between six months and 12 years old (Kaplan-Meier survival analysis; Wilcoxon test; $p=0.004$ ). The impaired clearance of parasitaemia in younger children with vivax malaria is shown for the first time in Latin America. It is speculated that CQ pharmacokinetics in young children with vivax malaria is distinct, but this specific population may also allow the detection of CQ-resistant parasites during follow-up, due to the lack of previous immunity.
\end{abstract}

Key words: malaria - Plasmodium vivax - paediatrics - chloroquine

Malaria is considered the most important parasitic disease in tropical areas, being responsible for a considerable amount of morbidity and mortality, especially in sub-Saharan Africa, where Plasmodium falciparum predominates, primarily affecting children and pregnant women (WHO 2012). In areas outside the African continent, Plasmodium vivax is responsible for more than $50 \%$ of malaria episodes and in many places, especially where elimination of transmission is within close sight, it is the predominant or even sole species causing malaria, as is the case in large regions of the Americas, the Indian subcontinent and the Pacific Region (WHO 2012). In the Americas, about half of malaria cases occur in Brazil (PAHO 2008). In Brazil, where more than 99\% of transmission occurs in the Amazon Region, there has been a considerable reduction in the incidence of the disease in recent years, with 241,806 cases reported in 2012 and with $P$. vivax responsible for $86.9 \%$ of these cases (Oliveira-Ferreira et al. 2010, MS 2013).

$P$. vivax is the most geographically widespread species that infects humans and the perception and widespread acceptance that $P$. vivax presents additional challenges for its elimination (Feachem et al. 2010) and that it can cause severe clinical manifestations and fatalities

doi: 10.1590/0074-0276130068

Financial support: FAPEAM, CNPq, PAIC (FMT-HVD/FAPEAM)

+ Corresponding authors: marcuslacerda.br@gmail.com,

amsiqueira@gmail.com

Received 25 December 2013

Accepted 2 June 2014
(Price et al. 2007, Lacerda et al. 2012a, b, Baird 2013) has led to increased interest in this parasite (Mueller et al. 2009, Carlton et al. 2011). Recent studies have demonstrated that $P$. vivax can often manifest with clinical complications, based on evidence of its occurrence in different settings, especially amongst children (Tjitra et al. 2008, Poespoprodjo et al. 2009, Tanwar et al. 2011, Lanca et al. 2012). Malaria in children is usually associated with higher rates of complications, therapeutic failure and mortality when compared with adults, regardless of the infecting species, rendering the need for specific attention to be devoted to children, a population that is usually neglected (Crawley et al. 2010).

Chloroquine (CQ) remains the first-line treatment for $P$. vivax asexual stages in most areas where this parasite is endemic, despite increasing reports of CQ resistance from many regions, especially from Southeast Asia (Baird 2009) and including evidence from the Brazilian Amazon, where the present work was performed (de Santana Filho et al. 2007). Children usually present a higher risk for antimalarial therapeutic failure, which, to a great extent, has been attributed to a lack of immunity against the parasite (Phyo et al. 2011). Nonetheless, there are more factors that must be taken into account, such as age-specific differences of pharmacodynamics and pharmacokinetic parameters (Ursing et al. 2014). The World Health Organization (WHO) recommends $\mathrm{CQ}$ administered in the dosage of $25 \mathrm{mg} / \mathrm{kg}$ divided over three days (WHO 2010). Notably, there is no recommendation for an age-specific individualisation of the CQ dosage, even considering the age-dependent changes in body composition and drug metabolism that influence the bioavailability of multiple drugs (Kearns et al. 2003) and the known large-distribution volume of this drug (Ducharme \& Farinotti 1996, Krishna \& White 1996). 
In this study, we aimed to evaluate the difference in the $P$. vivax parasitaemia clearance time amongst hospitalised children with exclusive use of CQ in a tertiary care hospital in the western Brazilian Amazon.

\section{SUBJECTS, MATERIALS AND METHODS}

Type of study - This was a retrospective analysis of parasitaemia clearance during the first five days of treatment in children with the diagnosis of $P$. vivax malaria admitted to the Paediatric Ward of the Tropical Medicine Foundation Dr Heitor Vieira Dourado (FMTHVD), a tertiary care centre for the diagnosis and treatment of infectious diseases located in Manaus (state of Amazonas, Brazil), from January 2003-January 2005.

Inclusion and exclusion criteria - Children were included in the study if they: (i) were under 12 years-old, (ii) had a confirmed positive thick blood smear for $P$. vivax mono-infection at admission, (iii) were having their first malarial infection (to avoid heterogeneous immune responses with potential effects on parasite clearance) and (iv) received the standard treatment for vivax malaria with CQ. Patients were excluded if one or more of the following criteria was present: (i) mixed infection (P. falciparum/P. vivax) in the thick blood smear, (ii) thick blood smears not performed on the first five days after the initiation of treatment, (ii) use of antimalarials in the 30 days preceding this episode and (iv) a sub-dose of CQ received (calculated based on the registered prescribed dose and the child's body weight on admission).

Malaria treatment and follow-up - Patients admitted to the ward received supervised treatment according to body weight and a daily thick blood smear was collected to assess parasitaemia clearance. During the study period, the treatment for $P$. vivax infection consisted of CQ $(10 \mathrm{mg} / \mathrm{kg}$ on day 1 and $7.5 \mathrm{mg} / \mathrm{kg}$ on days 2 and 3). In order to deliver the correct dosage, the CQ pills were crushed and diluted in water and the calculated volume was administered by a qualified nurse. If the patient vomited within $60 \mathrm{~min}$ after administration, the dose was repeated. Primaquine (PQ) is not recommended for infants below six months for age by the Brazilian National Malaria Control Program (NMCP). In this study, following a specific protocol of the institution, PQ was prescribed for patients older than six months of age $(0.5$ $\mathrm{mg} / \mathrm{kg} /$ day for 7 days) only at day 5 of treatment. This allowed for an evaluation of the CQ activity as monotherapy. Physicians were instructed to keep the patient admitted until parasite clearance; however, patients could be discharged at the physician's discretion according to clinical and laboratorial improvement.

Data retrieval - The following data were retrieved from the clinical charts: demographic and epidemiological characteristics (age, gender, previous exposure to malaria and body weight), clinical symptoms (vomiting and/ or diarrhoea), medical prescription and the total leukocyte count. The malaria diagnosis and parasite count were performed using Giemsa-stained thick blood smears. Two microscopists read the slide and registered the parasite counts per 200 leukocytes. The parasite density in parasites $/ \mathrm{mm}^{3}$ for each slide was calculated using the total leukocyte counts of each child. Slides for admitted patients were collected daily (usually in the morning).

Statistical analysis - Categorical variables were described in terms of proportions, while numerical variables were described as the mean and standard deviations if normally distributed or as median and interquartile range if not. Parasite densities, due to their skewed distribution, were described in terms of the geometric mean. The main aim of this study was to evaluate the parasite clearance time, which was defined as the day when a negative thick smear was detected, according to age group. A decision was made to categorise the groups based on age, either younger or older than six months, as age was a muchskewed variable and because six months of age is when the major changes in the percentage of total body water occur (Kearns et al. 2003). Age is also considered to be the major determinant of CQ blood concentrations (Krishna $\&$ White 1996) and the (NMCP) does not recommend the use of PQ in infants younger than six months of age. The Wilcoxon test and Kaplan-Meier curve were used to compare the survival function between groups. The analyses were performed in Stata $^{\circledR}$ v.11.2 (Statacorp ${ }^{\circledR}$, USA).

The study was approved by the Institutional Review Board of the FMT-HVD and the National Committee of Ethics in Science and Technology (protocol 25.001.011.792/2009-15).

\section{RESULTS}

During the study period, 135 patients younger than 12 years old were admitted to the Paediatric Ward of the FMT-HVD with a diagnosis of $P$. vivax malaria. The main reasons for admission were the presence of clinical complications in $48.1 \%$ (mainly anaemia and thrombocytopenia) and the presence of comorbidity in $14.1 \%$ of cases (including malnutrition in 2 cases and pneumonia in 2 children). Of the admitted patients, $76.3 \%$ were having their first episode of malaria, $57.8 \%$ were male and $30(22.2 \%)$ were younger than six months of age. In total,

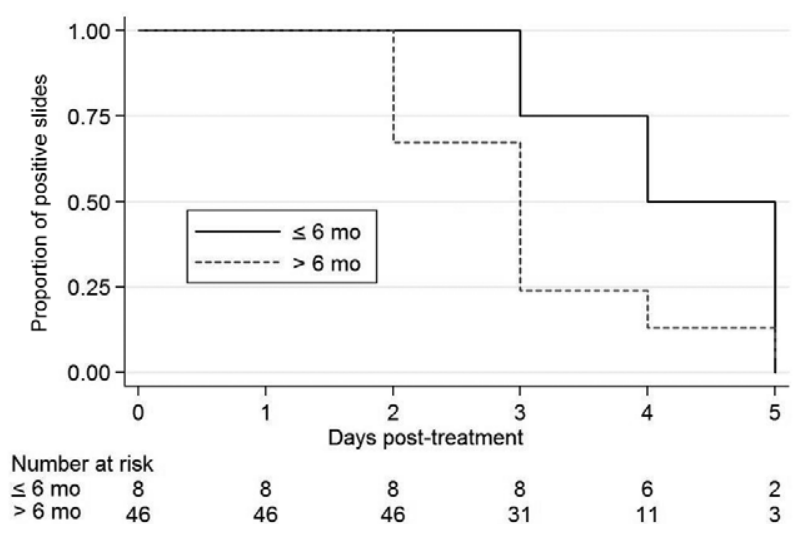

Kaplan-Meier curve shows the cumulative proportion of positive parasitaemia (thick blood smear) during the five-day follow-up after the beginning of therapy with chloroquine in hospitalised children (supervised administration at days 1,2 and 3, prior to beginning of primaquine, only at day 5). mo: months. 
TABLE

Clinical and demographic characteristics of the below six-month-old and above six-month-old groups

\begin{tabular}{lcc}
\hline & Below six months-old & Above six months-old \\
\hline $\mathrm{n}$ & 8 & 46 \\
Male gender [n (\%)] & $3(37.5)$ & $26(56.5)$ \\
Presented vomit during admission [n (\%)] & $3(37.5)$ & $25(54.4)$ \\
Presented diarrhoea during admission [n (\%)] & $0(0)$ & $11(23.9)$ \\
Parasite density at admission (parasites/mm ( $^{a}$ & $8,011(4,402-14,577)$ & $9,282(5,542-15,547)$ \\
Median number of days remained admitted (IQR) & $5.5(3)$ & $5(1)$ \\
\hline
\end{tabular}

$a$ : geometric mean (95\% confidence interval).

52 children received sub-dosage of $\mathrm{CQ}$, with a considerably higher proportion amongst patients in the younger than six months old group compared to the older age group ( $54.8 \%$ vs. $33.7 \%$; $p=0.033$, chi-square test). This finding highlights the vulnerability of this group, given the lack of specific paediatric formulations, to receiving under-dosage even in a supervised health facility setting. There were 54 patients who fulfilled the inclusion criteria for comparison of the time for parasitaemia clearance, with exclusion being due to short follow-up in 58 patients and previous malaria infection and recent exposure to CQ in 29 patients. Characteristics of the included patients are described in Table.

In Figure, the Kaplan-Meier curve shows that the group of children under six months of age took considerably longer to clear the peripheral parasitaemia when compared to older children. There is strong evidence that young infants exhibit a delay in achieving a negative blood slide, with a median number of four days required for young children, while older children required three days ( $p=0.007$; Wilcoxon test).

All children were discharged with a negative thick blood smear and no child was diagnosed as CQ-resistant to $P$. vivax after the 28-day follow-up in the Outpatient Clinics, even those children who were younger than six months of age and therefore did not take PQ.

\section{DISCUSSION}

It is estimated that more than 1.5 billion people live at risk of $P$. vivax infection (Gething et al. 2012). Along with reports from the literature describing a wide spectrum of clinical manifestations associated with severe vivax malaria in distinct settings (Tjitra et al. 2008, Kochar et al. 2009, Alexandre et al. 2010), there is evidence that children are a specially vulnerable population (Genton et al. 2008, Poespoprodjo et al. 2009, Lanca et al. 2012), highlighting the need to better understand the mechanisms and clinical complications associated with this infection (Mueller et al. 2009). Specifically regarding the concerns of increasing reports of $P$. vivax resistance to CQ in many areas of the world (Baird 2009), it is fundamental to characterise the proportion of therapeutic failure and the associated factors, because CQ remains the recommended drug to treat vivax malaria in most endemic areas (WHO 2010).
CQ has been a component of the first-line antimalarial arsenal for both adults and children for more than 60 years, especially due to its remarkable clinical efficacy and low cost (John 2003, Baird 2009). Widely used for the schizontocidal elimination of all species of Plasmodium, the dissemination of CQ-resistant $P$. falciparum has relegated its utility almost entirely to vivax malaria treatment, for which it is usually prescribed in a dosage of $25 \mathrm{mg} / \mathrm{kg}$ divided over three days irrespective of age group (John 2003, WHO 2010).

In our study, we found evidence of a difference in $P$. vivax parasitaemia clearance when comparing children younger than six months old with children between six months and 12 years old being treated for $P$. vivax infection. Other studies had already described worse responses to CQ amongst younger children with $P$. falciparum infection. In Guinea-Bissau, children younger than four years of age exhibited a higher failure rate when compared to older children, with both $25 \mathrm{mg} / \mathrm{kg}$ and $50 \mathrm{mg} / \mathrm{kg}$ total doses evaluated (Kofoed et al. 2007). A younger age was also one of the predictive factors for CQ treatment failure (along with body temperature and initial parasitaemia) in a multicentre study including Sub-Saharan African countries and Ecuador (Hamer et al. 2003). In a trial comparing CQ with dihydroartemisinin-piperaquine for $P$. vivax infection, young age was a strong independent predictor of treatment failure (Phyo et al. 2011).

The main factors that could explain the finding of impaired antimalarial efficacy in younger children are the different pharmacokinetics and lack of immunity found amongst this particular group. Immunity to malarial infection is an important factor to take into consideration when evaluating antimalarial efficacy and the lack of a proper immune response has been claimed as one of the main reasons for poorer therapeutic response amongst children (Phyo et al. 2011). However, it is not a factor to be considered in our study, because we have only evaluated children without previous malaria infection. It is also important to consider that children experience many changes throughout their development regarding drug absorption, distribution, metabolism and excretion, resulting in important distinctions in pharmacokinetic and pharmacodynamic parameters when compared to adults (Trape 2001, Kearns et al. 2003, Strolin Benedetti $\&$ Baltes 2003). Infants in the first six months of life 
have a much higher proportion of extracellular volume of water, corresponding to up to $40 \%$ of their body weight, especially when compared to older children and adults, for which the extracellular volume of water constitutes approximately 20\% (Strolin Benedetti \& Baltes 2003), which may have a considerable effect on the distribution of drugs through body tissues and, thus, an important impact on their blood levels. Pharmacokinetic studies have demonstrated that CQ's large apparent volume of distribution (between $100-1,000 \mathrm{~L} / \mathrm{kg}$ ) is the main determinant of its blood concentration during treatment for acute malaria attacks (Ducharme \& Farinotti 1996, Krishna \& White 1996). Therefore, it is reasonable to assume that the developmental changes in total body water proportions could influence the CQ blood levels and intra-erythrocyte concentration and at least to some extent explain the worse therapeutic response observed amongst younger age groups.

For many drugs, the simple body weight-adjusted dosage is not adequate for treatment of children, with recommendations requiring a more complex combination of age range and body weight or body-surface-area-based adjustments obtained from pharmacokinetic studies (Kearns et al. 2003, Strolin Benedetti \& Baltes 2003). Indeed, a recent study showed that young children being treated for $P$. falciparum infection have a considerably lower CQ blood level at day 7, with children younger than two years old needing to take double the dose $(50 \mathrm{mg} / \mathrm{kg})$ to achieve the same levels as 10-14-year-old children taking the regular dose ( $25 \mathrm{mg} / \mathrm{kg}$ ) (Ursing et al. 2014). This important study also demonstrated that high CQ doses are well tolerated by children and that the adjustment based on body-surface area would lead to less under dosage and blood-level variation than the usual body weight guidance, which could have several implications for drug resistance development among children (Ursing et al. 2014).

Studies have proposed changes in CQ dosage for children. Obua et al. (2008) conducted a population pharmacokinetics study in Uganda with two age-directed fixed-dose CQ and sulfadoxine combination treatments, concluding that the youngest children would benefit from increasing the dose. A study in Guinea-Bissau with children younger than five years old proposed that CQ doses should be increased to $50 \mathrm{mg} / \mathrm{kg}$ in order to obtain better results (Kofoed et al. 2007) with another study by the same group assuring the safety of this approach (Ursing et al. 2009).

When evaluated in the context of little or no resistance, CQ has a remarkable efficacy, with fast parasitaemia clearance and clinical recovery (Lal 1982, Walker et al. 1983, Khoromana et al. 1986, White et al. 1988). CQ achieves $80 \%$ bioavailability when taken orally (White et al. 1988, Krishna \& White 1996). In a study from Ghana, CQ administered by tablet was twice as accurate in delivering the drug compared to a syrup formulation (Ansah et al. 2001), thus reinforcing the belief that with proper usage, crushed tablets of CQ may provide a reliable alternative for children. In Brazil there is no paediatric formulation of antimalarials. In our study the CQ tablets were crushed and administered with water to provide the correct dosage $(\mathrm{mg} / \mathrm{kg})$ for each patient.
We observed a high proportion of underdosage in our study, especially amongst the youngest age group, which highlights the need to improve care for this particularly vulnerable and neglected population.

By restricting our analysis to children presenting their first malaria episode and with no evidence of drug underdosage, we aimed to reduce important known biases in order to assess the influence of age on the therapeutic response to CQ against $P$. vivax. There are, however, limitations to the retrospective design of our study that need to be mentioned, as well as the small sample size due to the scarcity of infants with malaria, which is also common in other endemic settings. The study was restricted to hospitalised patients, who are likely to present distinct characteristics compared to the general population, especially regarding age and the occurrence of clinical complications and comorbidities. The small sample size did not allow for the stratification of patients in narrower age groups and most likely detected a more direct age-response effect. Ideally, the parasite clearance time should be measured using systematic sampling according to time of medication (White 2011), which could have provided more accurate assessment. This is especially important as the average parasite clearance time observed in our cohort was considerably slower than expected - with a median of 30-60 h (Pukrittayakamee et al. 2000) - and this has been argued as early evidence of drug resistance (White 2011) and evidence of $P$. vivax resistance to CQ in our area (de Santana Filho et al. 2007), highlighting the need to better characterise the association of parasite clearance with long-term resistance in future studies. Finally, drug blood levels were not measured in our study, as there were no stored samples, which could have added further evidence of age-groupdependent differences in blood levels. The effect of PQ against sexual stages was not addressed in our study because no child used this hypnozoiticidal drug before five days of follow-up. As this 8-aminoquinoline could also synergise with CQ in its action against asexual stages (Pukrittayakamee et al. 1994), this could impact the parasitaemia clearance time in infants, which was a unique opportunity in terms of our objectives of evaluating the anti-schizontocidal activity of CQ.

This study demonstrated for the first time a slower parasitaemia clearance in children younger than six months of age with vivax malaria treated exclusively with $\mathrm{CQ}$ in the Brazilian Amazon. This finding is important as concerns regarding increasing resistance to $\mathrm{CQ}$ in the region need to be properly monitored and investigated. The fact that younger infants presented impaired therapeutic efficacy may be a reflection on this group acting as a sentinel for resistance, due to the group's immature immune system and erratic blood levels. It is important to properly characterise therapeutic failure by differentiating drug resistance from inadequate drug use. Special concern must be directed to reports of vivax malaria resistance to CQ restricted to younger populations (Talib et al. 1979, Memon et al. 1998, Khichi et al. 2005), for which resistance should be carefully characterised in order not to be confused with inadequate blood levels that could be attributed to the already discussed distinct pharmacokinetic and pharmacodynamics parameters (Ursing et al. 2014). 
It is paramount that children are included in malaria clinical trials and drug resistance monitoring studies in order not to neglect the potential for earlier detection of changing patterns of drug efficacy. Additionally, in a context of a renewed and reinforced agenda of malaria eradication, with $P$. vivax receiving a boost in attention due to its remarkable particularities, more attention should be directed to the adequate management of children, who constitute an especially vulnerable and neglected population. There is a clear and urgent need for larger and more detailed studies of $P$. vivax treatment assessing clinical response and pharmacokinetic properties in children, which need to consider stratified age range and body weight in their assessments.

\section{REFERENCES}

Alexandre MA, Ferreira CO, Siqueira AM, Magalhaes BL, Mourao MP, Lacerda MV, Alecrim M 2010. Severe Plasmodium vivax malaria, Brazilian Amazon. Emerg Infect Dis 16: 1611-1614.

Ansah EK, Gyapong JO, Agyepong IA, Evans DB 2001. Improving adherence to malaria treatment for children: the use of prepacked chloroquine tablets vs. chloroquine syrup. Trop Med Int Health 6: 496-504.

Baird JK 2009. Resistance to therapies for infection by Plasmodium vivax. Clin Microbiol Rev 22: 508-534.

Baird JK 2013. Evidence and implications of mortality associated with acute Plasmodium vivax malaria. Clin Microbiol Rev 26: 36-57.

Carlton JM, Sina BJ, Adams JH 2011. Why is Plasmodium vivax a neglected tropical disease? PLoS Negl Trop Dis 5: e1160.

Crawley J, Chu C, Mtove G, Nosten F 2010. Malaria in children. Lancet 375: 1468-1481.

de Santana Filho FS, Arcanjo AR, Chehuan YM, Costa MR, Martinez-Espinosa FE, Vieira JL, Barbosa MG, Alecrim WD, Alecrim MG 2007. Chloroquine-resistant Plasmodium vivax, Brazilian Amazon. Emerg Infect Dis 13: 1125-1126.

Ducharme J, Farinotti R 1996. Clinical pharmacokinetics and metabolism of chloroquine. Focus on recent advancements. Clin Pharmacokinet 31: 257-274.

Feachem RG, Phillips AA, Hwang J, Cotter C, Wielgosz B, Greenwood BM, Sabot O, Rodriguez MH, Abeyasinghe RR, Ghebreyesus TA, Snow RW 2010. Shrinking the malaria map: progress and prospects. Lancet 376: 1566-1578.

Genton B, D’Acremont V, Rare L, Baea K, Reeder JC, Alpers MP, Muller I 2008. Plasmodium vivax and mixed infections are associated with severe malaria in children: a prospective cohort study from Papua New Guinea. PLoS Med 5: e127.

Gething PW, Elyazar IR, Moyes CL, Smith DL, Battle KE, Guerra CA, Patil AP, Tatem AJ, Howes RE, Myers MF, George DB, Horby P, Wertheim HF, Price RN, Mueller I, Baird JK, Hay SI 2012. A long neglected world malaria map: Plasmodium vivax endemicity in 2010. PLoS Negl Trop Dis 6: e1814.

Hamer DH, MacLeod WB, Addo-Yobo E, Duggan CP, Estrella B, Fawzi WW, Konde-Lule JK, Mwanakasale V, Premji ZG, Sempertegui F, Ssengooba FP, Yeboah-Antwi K, Simon JL 2003. Age, temperature and parasitaemia predict chloroquine treatment failure and anaemia in children with uncomplicated Plasmodium falciparum malaria. Trans $R$ Soc Trop Med Hyg 97: 422-428.

John CC 2003. Drug treatment of malaria in children. Pediatr Infect Dis J 22: 649-651.
Kearns GL, Abdel-Rahman SM, Alander SW, Blowey DL, Leeder JS, Kauffman RE 2003. Developmental pharmacology - drug disposition, action and therapy in infants and children. $N$ Engl J Med 349: 1157-1167.

Khichi QK, Channar MS, Wairraich MI, Butt A 2005. Chloroquine resistant malaria in neonates. J Coll Physicians Surg Pak 15: 34-36.

Khoromana CO, Campbell CC, Wirima JJ, Heymann DL 1986. In vivo efficacy of chloroquine treatment for Plasmodium falciparum in Malawian children under five years of age. Am J Trop Med Hyg 35: 465-471.

Kochar DK, Das A, Kochar SK, Saxena V, Sirohi P, Garg S, Kochar A, Khatri MP, Gupta V 2009. Severe Plasmodium vivax malaria: a report on serial cases from Bikaner in northwestern India. Am J Trop Med Hyg 80: 194-198.

Kofoed PE, Ursing J, Poulsen A, Rodrigues A, Bergquist Y, Aaby P, Rombo L 2007. Different doses of amodiaquine and chloroquine for treatment of uncomplicated malaria in children in GuineaBissau: implications for future treatment recommendations. Trans R Soc Trop Med Hyg 101: 231-238.

Krishna S, White NJ 1996. Pharmacokinetics of quinine, chloroquine and amodiaquine. Clinical implications. Clin Pharmacokinet 30: 263-299.

Lacerda MV, Mourao MP, Alexandre MA, Siqueira AM, Magalhaes BM, Martinez-Espinosa FE, Filho FS, Brasil P, Ventura AM, Tada MS, Couto VS, Silva AR, Silva RS, Alecrim MG 2012a. Understanding the clinical spectrum of complicated Plasmodium vivax malaria: a systematic review on the contributions of the Brazilian literature. Malar J 11: 12.

Lacerda MV, Fragoso SC, Alecrim MG, Alexandre MA, Magalhaes BM, Siqueira AM, Ferreira LC, Araujo JR, Mourao MP, Ferrer M, Castillo P, Martin-Jaular L, Fernandez-Becerra C, del Portillo H, Ordi J, Alonso PL, Bassat Q 2012a. Postmortem characterization of patients with clinical diagnosis of Plasmodium vivax malaria: to what extent does this parasite kill? Clin Infect Dis 55: e67-74.

Lal H 1982. A comparative trial of oral chloroquine and oral cotrimoxazole in vivax malaria in children. Am J Trop Med Hyg 31: 438-440.

Lanca EF, Magalhaes BM, Vitor-Silva S, Siqueira AM, Benzecry SG, Alexandre MA, O’Brien C, Bassat Q, Lacerda MV 2012. Risk factors and characterization of Plasmodium vivax-associated admissions to pediatric intensive care units in the Brazilian Amazon. PLoS ONE 7: e35406.

Memon IA, Kanth N, Murtaza G 1998. Chloroquine resistant malaria in children. J Pak Med Assoc 48: 98-100.

MS - Ministério da Saúde Brasil 2013. Situação epidemiológica da malária no Brasil, 2000 a 2011. Bol Epidemiol 44: 1-16.

Mueller I, Galinski MR, Baird JK, Carlton JM, Kochar DK, Alonso PL, del Portillo HA 2009. Key gaps in the knowledge of Plasmodium vivax, a neglected human malaria parasite. Lancet Infect Dis 9: 555-566.

Obua C, Hellgren U, Ntale M, Gustafsson LL, Ogwal-Okeng JW, Gordi T, Jerling M 2008. Population pharmacokinetics of chloroquine and sulfadoxine and treatment response in children with malaria: suggestions for an improved dose regimen. $\mathrm{Br} \mathrm{J} \mathrm{Clin}$ Pharmacol 65: 493-501.

Oliveira-Ferreira J, Lacerda MV, Brasil P, Ladislau JL, Tauil PL, Daniel-Ribeiro CT 2010. Malaria in Brazil: an overview. Mal J 9: 115.

PAHO - Pan American Health Organization 2008. Malaria in the Americas - Time series epidemiological data from 2000 to 2007. Available from: paho.org/English/AD/DPC/CD/mal-reg-country-epi-data-2007.pdf. 
Phyo AP, Lwin KM, Price RN, Ashley EA, Russell B, Sriprawat K, Lindegardh N, Singhasivanon P, White NJ, Nosten F 2011. Dihydroartemisinin-piperaquine versus chloroquine in the treatment of Plasmodium vivax malaria in Thailand: a randomized controlled trial. Clin Infect Dis 53: 977-984.

Poespoprodjo JR, Fobia W, Kenangalem E, Lampah DA, Hasanuddin A, Warikar N, Sugiarto P, Tjitra E, Anstey NM, Price RN 2009. Vivax malaria: a major cause of morbidity in early infancy. Clin Infect Dis 48: 1704-1712.

Price RN, Tjitra E, Guerra CA, Yeung S, White NJ, Anstey NM 2007. Vivax malaria: neglected and not benign. Am J Trop Med Hyg 77 (Suppl.): 79-87.

Pukrittayakamee S, Chantra A, Simpson JA, Vanijanonta S, Clemens R, Looareesuwan S, White NJ 2000. Therapeutic responses to different antimalarial drugs in vivax malaria. Antimicrob Agents Chemother 44: 1680-1685.

Pukrittayakamee S, Vanijanonta S, Chantra A, Clemens R, White NJ 1994. Blood stage antimalarial efficacy of primaquine in Plasmodium vivax malaria. J Infect Dis 169: 932-935.

Strolin Benedetti M, Baltes EL 2003. Drug metabolism and disposition in children. Fundam Clin Pharmacol 17: 281-299.

Talib VH, Kiran PC, Talib NJ, Choudhury M 1979. Chloroquineresistant Plasmodium vivax malaria in infancy and childhood. Indian J Pediatr 46: 158-162.

Tanwar GS, Khatri PC, Sengar GS, Kochar A, Kochar SK, Middha S, Tanwar G, Khatri N, Pakalapati D, Garg S, Das A, Kochar DK 2011. Clinical profiles of 13 children with Plasmodium vivax cerebral malaria. Ann Trop Paediatr 31: 351-356.
Tjitra E, Anstey NM, Sugiarto P, Warikar N, Kenangalem E, Karyana M, Lampah DA, Price RN 2008. Multidrug-resistant Plasmodium vivax associated with severe and fatal malaria: a prospective study in Papua, Indonesia. PLoS Med 5: e128.

Trape JF 2001. The public health impact of chloroquine resistance in Africa. Am J Trop Med Hyg 64: 12-17.

Ursing J, Kofoed PE, Rodrigues A, Bergqvist Y, Rombo L 2009. Chloroquine is grossly overdosed and overused but well tolerated in Guinea-Bissau. Antimicrob Agents Chemother 53: 180-185.

Ursing J, Eksborg S, Rombo L, Bergqvist Y, Blessborn D, Rodrigues A, Kofoed P-E 2014. Chloroquine is grossly under dosed in young children with malaria: implications for drug resistance. PLoS ONE 9: e86801.

Walker O, Dawodu AH, Adeyokunnu AA, Salako LA, Alvan G 1983. Plasma chloroquine and desethylchloroquine concentrations in children during and after chloroquine treatment for malaria. $\mathrm{Br} \mathrm{J}$ Clin Pharmacol 16: 701-705.

White NJ 2011. The parasite clearance curve. Malar J 10: 278.

White NJ, Miller KD, Churchill FC, Berry C, Brown J, Williams SB, Greenwood BM 1988. Chloroquine treatment of severe malaria in children. Pharmacokinetics, toxicity and new dosage recommendations. N Engl J Med 319: 1493-1500.

WHO - World Health Organization 2010. Guidelines for the treatment of malaria. Available from: http://whqlibdoc.who.int/ publications/2010/9789241547925_eng.pdf.

WHO - World Health Organization 2012. World malaria report 2012. Available from: who.int/malaria/publications/world_malaria report_2012/en/. 